\title{
CONTRIBUTIONS TO THE SHAPING OF THE SUCCESSFUL COACH PERSONALITY PROFILE
}

\author{
Radu PREDOIU1 ${ }^{1}$, Alexandra PREDOIU ${ }^{1 *}$, Germina COSMA², \\ Aura BOTA ${ }^{1}$, Georgeta MITRACHE ${ }^{1}$
}

\author{
${ }^{I}$ National University of Physical Education and Sports, Faculty of Physical Education and Sport, \\ 140 Constantin Noica Street, Bucharest, Romania \\ ${ }^{2}$ University of Craiova, Faculty of Physical Education and Sport, 146 Brestei Street, Craiova, Romania \\ *corresponding author: alexandra.predoiu@yahoo.com
}

https://doi.org/10.52846/jskm/37.2021.1.1

\section{Abstract:}

Exceptional sports performances cannot be obtained without maximizing the personality of the coaches. Personality traits are characterized by generality (manifested in different situations) and relative stability (do not change accidentally). Through this paper we want to contribute to the shaping of the top coach personality profile. 16 successful Romanian coaches from eleven sport branches (13 men and 3 women), with an average age of 58.9 years, took part in the research. The NEO-FFI questionnaire, developed by Costa Jr. and McCrae, calibrated for the Romanian population, was used. Analyzing the personality profiles of successful coaches we could highlight the fact that: $93.75 \%$ are focused on goals; $87.5 \%$ are motivated; $81.25 \%$ of successful coaches are selfless and optimistic; $75 \%$ are forgiving (anger control); $68.75 \%$ are charismatic; $50 \%$ are progressive, respectively $31.25 \%$ are traditional (decisional style); $56.25 \%$ of specialists are aspirational, and $43.75 \%$ are hardworking (learning style); $56.25 \%$ are adaptive, respectively $37.5 \%$ are hyposensitive (defense style). The study also presents the level at which 13 professional competencies are manifested, the five major personality factors (Big Five Model) and their facets: Self-esteem, Emotionality, Sociability, Activism, Curiosity, Flexibility, Confidence vs. Suspicion, Politeness, Productivity and Organization. The results of our research represent particularly valuable resources in the training process of young coaches (and not only).

Keywords: BIG FIVE Model, personality, successful coach, sport.

\section{Introduction}

The process of personal development is invaluable for coaches (and not only), our work increasing the awareness of the essential role that sports performance programmers (coaches) have in obtaining exceptional sports results. The development of the coaches' personality is very important - we mention, however, that this topic has been less addressed in the literature (Sheehy et al., 2019) although since the 20's Coleman Grifftith ("Father of Sports Psychology" in the US), has stated that among the tasks of the sports psychologist is the one to teach young and inexperienced coaches about the psychological principles used by successful and experienced coaches (we include attitudes, behaviors, emotional reactions, phenomena that fall within the sphere of personality).

Over time, factor analysis studies have led to the recognition of the existence of five key factors in personality structure, known as the BIG FIVE model. According to this model, the five factors are: Extraversion,
Pleasantness, Conscientiousness, Emotional Stability, commonly known as Neuroticism (shows how self-controlled, anxious or irritable the person is) and Openness to experiences - the person's intellectual curiosity, attention inner life etc. (Lounsbury et al., 2009; Predoiu, 2017).

Can we say that a certain personality profile determines superior sports performance? In 2020, we were able to highlight a series of personality traits specific to top coaches (there is a significant difference compared to the scores obtained by young coaches, at the beginning of their careers). We present, below, the 9 professional traits and competencies that we can say are specific to successful coaches - the score being significantly higher / lower, by comparing it with the values obtained by novice coaches (Predoiu et al., 2020): Conscientiousness, Neuroticism, Agreeableness, delegation ability, decisionmaking ability, leadership ability, ability to develop others, independence in work and locus of control (internal locus of control). 
The top coach is, indisputably, a leader, an inspirational figure for athletes / team, motivating and guiding athletes in their work. The leader, in sports, possesses important intellectual abilities, attention efficiency and superior performances considering vigilance (Predoiu et al., 2017; Grigore et al., 2017). Visualizing solutions based on context, creative thinking, competition planning skills, training, and meta-cognitive skills are attributes of a good coach (Mumford et al., 2016; Mesquita et al., 2012). Among the characteristics of a successful coach we also highlight: he has the ability to positively influence the learning and performance of athletes; understands athletes, has technical knowledge and is concerned with their continuing education; is a good communicator, flexible in managing problems, helping athletes cope with the negative stress of the competition and the training process (Zhang et al., 2018; Myers et al., 2017; Jones et al., 2004).

Prophet et al. (2017) emphasizes the importance of the quality of interactions with athletes, interactions both inside and outside the training process, while Gilbert et al. (2006) talk about the tendency of successful coaches to invest a consistent time in professional and personal development.

The aim of our study is to capture a typology of top coaches - both globally (in the case of the 16 successful coaches investigated) and depending on the category of the sport practiced - starting from the combination of scores obtained for the components of the BIG FIVE model. At the same time, the paper aims to highlight the level at which the facets of the 5 major personality factors are manifested (in the case of top coaches) depending on the sport practiced. The facets of the five major personality factors are: Selfesteem, Emotionality, Sociability, Activism, Curiosity, Flexibility, Confidence vs. Suspicion, Politeness, Productivity and Organization.

\section{Materials and method Participants}

16 successful Romanian coaches (13 men and 3 women) with an average age of 58.9 years took part in the study. 8 coaches won, with trained athletes, gold, silver or bronze medals in the Olympic Games (we mention, also, the participation, in our paper, of the most successful coach in the world - declared by the World Records Academy ), 5 coaches registered outstanding performances in the World Championships (trained athletes who occupied the first steps of the podium), and 3 coaches obtained remarkable results at the European Championships (the trained athletes are European champions or vice-champions). We highlight the sport practiced (and the category of sport practiced) and the number of specialists:

- Individual sports: artistic gymnastics, aerobic gymnastics, rhythmic gymnastics, tennis, karate, Greco-Roman wrestling, kayaking-canoeing, skiing and fencing - 14 specialists.

- Team sports: handball and rugby - 2 specialists.

- Sports with direct contact with the opponent: handball, rugby, karate, Greco-Roman wrestling and fencing - 5 specialists.

- Sports without direct contact with the opponent: artistic gymnastics, aerobic gymnastics, rhythmic gymnastics, tennis, skiing and kayaking - 11 specialists.

- Heuristic sports: tennis, karate, handball, rugby, Greco-Roman wrestling and fencing 7 specialists.

- Algorithmic sports: artistic gymnastics, aerobics, rhythmic gymnastics, skiing and kayaking - 9 specialists.

\section{Measures}

The NEO-FFI questionnaire was used, being one of the most famous instruments that measure personality traits. The questionnaire (developed by P. T. Costa Jr. and R. McCrae) was translated and calibrated for the Romanian population (Iliescu et al., 2008). NEO-FFI applies from the age of 14 and consists of 60 verbal items (measured on a 5step Likert scale).

The questionnaire measures the five classic components of the BIG FIVE model (each major personality factor comprising two facets), but also provides information about the following 13 professional competencies: orientation towards change, delegation capacity, decision-making capacity, ability to 
develop others, adherence to organizational policies, leadership skills, independence in work, place of control (locus of control), orientation towards action, risk-taking, facilitation, business efficiency and entrepreneurship. At the same time, starting from the combination of scores obtained for the components of the BIG FIVE model, the profile (automatically generated) provides particularly important information on: decision style, interaction style, impulse control, learning style, psychological wellbeing, task orientation, anger control, character orientation and defensive style.

\section{Procedure}

The data collection process took place in the last 3 years (a long process, coaches with exceptional results internationally being relatively difficult to find). The NEO-FFI personality questionnaire was applied online to the coaches, using a computerized platform. The coaches had the option to withdraw from the research at any time. We specify that the data were treated confidentially, and the written informed consent (in the case of successful coaches) was obtained.

\section{Results}

Table 1. Descriptive statistics - major personality factors and the 13 professional competencies investigated by the NEO-FFI questionnaire

\begin{tabular}{|c|c|}
\hline Personality dimensions & $\begin{array}{c}\text { Top coaches } \\
M(S D)\end{array}$ \\
\hline Neuroticism & $18.62(19.56)$ \\
\hline Extraversion & $75.37(22.78)$ \\
\hline Openness to experiences & $57.12(25.45)$ \\
\hline Agreeableness & $67.94(27.54)$ \\
\hline Conscientiousness & $88.06(12.24)$ \\
\hline Orientation towards change & $84.05(14.25)$ \\
\hline Decision making ability & $86.06(14.11)$ \\
\hline Delegation capacity & $82.12(17.82)$ \\
\hline Adherence to organizational policies & $45.12(25.38)$ \\
\hline The development of others & $83.00(18.56)$ \\
\hline Leadership & $85.62(16.72)$ \\
\hline Locus of control & $83.68(14.61)$ \\
\hline Independence at work & $77.87(19.82)$ \\
\hline Action orientation & $22.94(22.13)$ \\
\hline Business efficiency & $82.93(19.91)$ \\
\hline Facilitation & $35.93(36.64)$ \\
\hline
\end{tabular}




\begin{tabular}{|c|c|}
\hline Entrepreneurship & $82.12(17.78)$ \\
\hline Taking risks & $55.05(25.73)$ \\
\hline
\end{tabular}

Notes: $0-30$ is a low score; 30-40 score slightly below average; 40-60 is an average score; 60-70 score slightly above average; 70-100 is a high score.

Analyzing Table 1 we can conclude that elite coaches are calm and relatively devoid of negative emotional states (Neuroticism), resist momentary impulses, manage to control their reactions and are aware of the impact of their own behavior on external situations (locus of control). Also, in a conflict, they tend to support one of the parties involved, depending on personal preferences (we notice a slightly below average score in the case of Facilitation).

1) The typology of top coaches - globally (the 16 successful coaches) - starting from the combination of scores obtained in the case of model components BIG FIVE

We recall the five classic components of the Big Five model: Neuroticism (Emotional Stability), Extraversion, Openness to
Experiences, Pleasantness and Conscientiousness. Starting from the combination of scores obtained for these major personality factors, the personality profile (automatically generated), highlights: impulse control, interaction style, learning style, decision style, anger control, task orientation, defense style, well-being psychological and character orientation. We present the results of the 16 coaches with performances at the Olympic Games, World or European Championships.

\section{Legend:}

Neuroticism - N; Extraversion - E; Openness - O; Pleasantness - P; Conscientiousness - C; High score: $\mathrm{N}^{+}, \mathrm{E}^{+}, \mathrm{O}^{+}, \mathrm{P}^{+}, \mathrm{C}^{+}$; ; ;Low Score: $\mathrm{N}^{--}, \mathrm{E}^{--}, \mathrm{O}^{--}, \mathrm{P}^{--}, \mathrm{C}^{--}$.

Table 2. Typology of top coaches - globally (gross scores and percentages)

\begin{tabular}{|c|c|}
\hline \multicolumn{2}{|c|}{$\begin{array}{c}\text { TOP COACHES } \\
\end{array}$} \\
\hline \multicolumn{2}{|c|}{ Interaction style (from scores for $\mathrm{E}$ and $\mathrm{A}$ ) } \\
\hline Charismatic $\mathrm{E}^{+} \mathrm{P}^{+}$ & $11(68.75 \%)$ \\
\hline Leadership $\mathrm{E}^{+} \mathrm{P}^{--}$ & $3(18.75 \%)$ \\
\hline Participativ $\mathrm{E}^{--} \mathrm{P}^{+}$ & $2(12.5 \%)$ \\
\hline Withdrawn $\mathrm{E}^{--} \mathrm{P}^{--}$ & $0(0 \%)$ \\
\hline \multicolumn{2}{|c|}{ Impulse Control (from scores for C and N) } \\
\hline Objectives focused $\mathrm{C}^{+} \mathrm{N}^{--}$ & $15(93.75 \%)$ \\
\hline over-controlled $\mathrm{C}^{+} \mathrm{N}^{+}$ & $1(6.25 \%)$ \\
\hline under-controlled $\mathrm{C}^{--} \mathrm{N}^{+}$ & $0(0 \%)$ \\
\hline Relaxed $\mathrm{C}^{--} \mathrm{N}^{--}$ & $0(0 \%)$ \\
\hline \multicolumn{2}{|c|}{ Character Orientation (from scores for A and C) } \\
\hline Altruistic/selfless $\mathrm{P}^{+} \mathrm{C}^{+}$ & $13(81.25 \%)$ \\
\hline Personal needs orientation $\mathrm{P}^{--} \mathrm{C}^{+}$ & $3(18.75 \%)$ \\
\hline unmotivated $\mathrm{P}^{--} \mathrm{C}^{--}$ & $0(0 \%)$ \\
\hline Generous $\mathrm{P}^{+} \mathrm{C}^{--}$ & $0(0 \%)$ \\
\hline \multicolumn{2}{|c|}{$\begin{array}{c}\text { Task Orientation (from scores for } \mathbf{E} \text { and } \mathbf{C} \text { ) } \\
\end{array}$} \\
\hline Motivated $\mathrm{E}^{+} \mathrm{C}^{+}$ & $14(87.5 \%)$ \\
\hline Methodical E-- $\mathrm{C}^{+}$ & $2(12.5 \%)$ \\
\hline Hedonic $\mathrm{E}^{+} \mathrm{C}^{--}$ & $0(0 \%)$ \\
\hline Passive $\mathrm{E}^{--} \mathrm{C}^{--}$ & $0(0 \%)$ \\
\hline \multicolumn{2}{|c|}{$\begin{array}{l}\text { decisional style (from scores for A and D) } \\
\end{array}$} \\
\hline Traditional $\mathrm{P}^{+} \mathrm{O}^{--}$ & $5(31.25 \%)$ \\
\hline Progressive $\mathrm{P}^{+} \mathrm{O}^{+}$ & $8(50 \%)$ \\
\hline
\end{tabular}




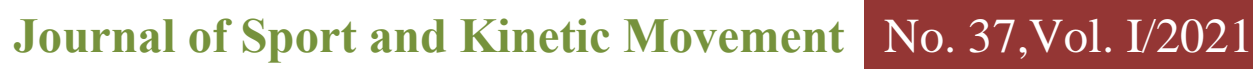

\begin{tabular}{cc}
\hline Dogmatic $\mathrm{P}^{--} \mathrm{O}^{--}$ & $2(12.25 \%)$ \\
\hline Liberal $\mathrm{P}^{--} \mathrm{O}^{+}$ & $1(6.25 \%)$ \\
\hline \multicolumn{1}{c}{ Learning style (from scores for D and C) } \\
\hline Curious $\mathrm{O}^{+} \mathrm{C}^{--}$ & $0(0 \%)$ \\
\hline Aspirational $\mathrm{O}^{+} \mathrm{C}^{+}$ & $9(56.25 \%)$ \\
\hline Practical $\mathrm{O}^{--} \mathrm{C}^{--}$ & $0(0 \%)$ \\
\hline Hardworking/dilligent $\mathrm{O}^{--} \mathrm{C}^{+}$ & $7(43.75 \%)$ \\
\hline Psychological wellbeing (from scores for $\mathbf{E}$ and $\mathbf{N})$ \\
\hline Optimistic $\mathrm{E}^{+} \mathrm{N}^{--}$ & $13(81.25 \%)$ \\
\hline Emotional $\mathrm{E}^{+} \mathrm{N}^{+}$ & $1(6.25 \%)$ \\
\hline Detached $\mathrm{E}^{--} \mathrm{N}^{--}$ & $2(12.5 \%)$ \\
\hline Pessimistic $\mathrm{E}^{--} \mathrm{N}^{+}$ & $0(0 \%)$ \\
\hline \multicolumn{1}{c}{ Defense style (from scores for $\mathbf{N}$ and $\mathbf{D})$} \\
\hline disadaptive $\mathrm{N}^{+} \mathrm{O}^{--}$ & $1(6.25 \%)$ \\
\hline Hyper-sensitive $\mathrm{N}^{+} \mathrm{O}^{+}$ & $0(0 \%)$ \\
\hline Hyposensitive $\mathrm{N}^{--} \mathrm{O}^{--}$ & $6(37.5 \%)$ \\
\hline Adaptative $\mathrm{N}^{--} \mathrm{O}^{+}$ & $9(56.25 \%)$ \\
\hline Anger control (from scores for $\mathbf{N}$ and $\mathbf{A})$ \\
\hline Temperamental $\mathrm{N}^{+} \mathrm{P}^{--}$ & $0(0 \%)$ \\
\hline Timid $\mathrm{N}^{+} \mathrm{P}^{+}$ & $1(6.25 \%)$ \\
\hline Cold-blooded $\mathrm{N}^{--} \mathrm{P}^{--}$ & $3(18.75 \%)$ \\
\hline forgiving $\mathrm{N}^{--} \mathrm{P}^{+}$ & $12(75 \%)$ \\
\hline
\end{tabular}

We emphasize the dominant values in the case of top coaches: $68.75 \%$ are charismatic; $93.75 \%$ are focused on objectives; $81.25 \%$ of successful coaches are altruistic/selfless; $87.5 \%$ are motivated (this is the task orientation); $50 \%$ are progressive, respectively $31.25 \%$ are traditional (decisional style); $56.25 \%$ of specialists are aspirational, and $43.75 \%$ are hardworking/dilligent (learning style); $81.25 \%$ are optimistic; $56.25 \%$ are adaptive, respectively $37.5 \%$ are hyposensitive (defense style); $75 \%$ are forgiving (anger control). The differences highlighted are normal, the sports performance being idiosyncratic. However, we manage to observe certain prevailing trends (see Table 2), very important aspects for future coaches (and not only), in the process of personal and professional development. We present the significance of the most important dimensions highlighted (NEOFFI-Plus Extended Report):

- $\quad$ Charismatic - These people sincerely enjoy the company of others, being strongly attached to old friends, but at the same time showing enthusiasm when they meet new people. These people enjoy talking to others on various topics, feeling comfortable in their company. Usually these people are popular in their social environment.

- Goal-centered - These people have a very clear picture of the goals they want to achieve. Moreover, they have the ability to overcome obstacles that stand in the way of achieving goals through perseverance and organization. They recover very quickly from failures and can manage the immediate dissatisfaction of needs to achieve an important goal.

- $\quad$ Altruistic - These people deliberately and organizedly channel their efforts into activities in order to help others. Persists in overcoming obstacles in order to be useful to others.

- Motivated - These people are considered efficient, having the ability to work at a steady pace and with an alert personal tempo. Most of the time these people are interested in their own professional development and evolution, being able to follow a pre-established program or plan. Sometimes these people try to impose their 
work style on those around them, which they consider to be very effective

- $\quad$ Progressive - These people tend to be oriented towards novelty and change, while being interested in applying new solutions, especially when they have a positive impact on others. They trust human nature and when making decisions they are careful to make changes in the interests of others. These people are usually very effective in helping others grow and progress.

- Traditional - These people are interested in the well-being of others, but unlike the progressive type, they believe that well-being can be achieved by respecting traditional norms and values. They tend to make decisions in the spirit of laws and values generally promoted at the social level. For these people, following the rules already established is the best way to ensure the wellbeing of society in general.

- $\quad$ Aspirational - These people combine a pronounced curiosity with a well-developed capacity for personal organization, thus obtaining outstanding results academically or in general contexts that require learning. These people generally have high aspirations and often find creative ways to solve the problems they face. They have great chances to succeed in their activity.

- Dilligent/hard-working - These people are perceived as methodical and organized, trying to follow the rules and procedures. They prefer structured approaches in which they are explained step by step and may have difficulty managing exceptional situations. These people are effective in learning by heart and resuming the resolution procedures they have previously learned. They have a strong need to get involved in structured activities and to complete what they set out to do.

- Optimistic - These people convey a good mood in the social environment, often without worries or emotional problems. When dealing with frustrations or disappointments, these people may be sad at times, but they have the ability to get over them quickly. Moreover, they tend to enjoy life in general and are usually focused on the future, not the past.

- $\quad$ Adaptive - People characterized by adaptive style tend to be aware of the conflicts, stress or threats to which they are exposed, while being able to discover adaptive ways to manage these situations. They tend to formulate more and more effective ways to solve emotional problems, their psychological tone being positive and optimistic.

- $\quad$ Hyposensitive - Hyposensitive people tend to minimize the importance or intensity of the emotional feelings they have. In order to overcome any difficult moments from an emotional point of view, they will tend to get involved in concrete actions. These people tend to believe in a higher entity that has an important role in solving difficult personal problems.

- Forgiving - People with this combination of scores tend not to directly express anger and negative feelings. Even when insulted, these people prefer to forgive and forget about the incident, without getting into controversy. These people also understand the perspective of others and often try to reach a common, mutually beneficial point of view.

2) The typology of the top coaches depending on the sport practiced - starting from the combination of the results obtained in the case of the components of the BIG FIVE model

Due to the small sample of investigated specialists - especially in the case of team sports, we will be careful in interpretation (in the case of this category). However, the investigated coaches are special sports personalities, who have made history internationally, the number of Romanian coaches who can also enjoy sports performances (at the Olympic Games, at the World or European Championships) being relatively small. We specify the categories we will focus on: individual sports, with direct contact with the opponent or without direct contact, algorithmic and heuristic sports. 
Following the analysis of the personality profiles of the top coaches, we highlight the following aspects:

- Regarding the style of interaction (from the scores for Extraversion and Pleasure) successful coaches are predominantly Charismatic (regardless of the sport practiced); they are followed by coaches with the interaction style called Leadership. We notice a slight tendency for coaches in sports in which the contact with the opponent is direct (handball, rugby, karate, Greco-Roman wrestling and fencing) to be, to a greater extent, charismatic (compared to other specialists).

- $\quad$ Regarding the decision-making style (from the scores for Pleasantness and Openness) we could notice that the top coaches, regardless of the sport category practiced, are predominantly Progressive, followed by Traditional.

- $\quad$ Referring to the learning style (from the scores for Openness and Consciousness), coaches in algorithmic sports where the contact with the opponent is not direct tend to be Aspirational, while specialists in heuristic sports where contact with the opponent is direct tend to be predominantly dilligent.

- In the case of task orientation (from scores for Extraversion and Conscientiousness), coaches with outstanding performance are predominantly Motivated, regardless of the sport practiced. We also specify the fact that Methodical coaches are more active in individual sports, algorithmic or without direct contact with the opponent.

- In relation to psychological wellbeing (from the scores for Extraversion and
Neuroticism) successful coaches are predominantly Optimistic (regardless of the sport category practiced). We mention a slight tendency for the Detached coaches to be more active in sports where the contact with the opponent is not direct.

- $\quad$ Analyzing the impulse control (from the scores for Conscientiousness and Neuroticism) we can see that the top coaches are focused on goals.

- $\quad$ Regarding the style of defense (from the scores for Neuroticism and Opening) we note that coaches with outstanding performance who work in individual sports, without direct contact with the opponent or algorithms, are predominantly Adaptive; instead, in the case of specialists in heuristic sports and where the contact with the opponent is direct, we highlight the tendency to be predominantly Hyposensitive.

- Investigating the character orientation (from the scores for Pleasantness and Conscientiousness) the top coaches, regardless of the sport practiced, are predominantly Altruistic; we also emphasize the tendency of coaches in algorithmic sports and without direct contact with the opponent to be focused on their own needs.

- In case of anger control (from scores for Neuroticism and Pleasure) - successful coaches (regardless of the sport practiced) are predominantly Forgiving; we also specify the tendency of some specialists (regardless of the investigated sports category) to belong to the typology - Cold-blooded.

3) The level at which the facets of the 5 major personality factors are manifested, depending on the sport practiced

Table 3. The level at which the personality dimensions of successful coaches are manifested (facets of major personality factors - BIG FIVE model)

\begin{tabular}{|c|c|c|c|c|c|c|}
\hline \multicolumn{7}{|c|}{ TOP COACHES } \\
\hline \multicolumn{7}{|c|}{$\begin{array}{l}\text { SPORT } \\
\end{array}$} \\
\hline $\begin{array}{c}\text { Fațete ale } \\
\text { personalității }\end{array}$ & $\begin{array}{c}\text { Individual } \\
M\end{array}$ & $\begin{array}{c}\text { De echipă } \\
M\end{array}$ & $\begin{array}{c}\text { DC } \\
M\end{array}$ & $\begin{array}{c}\text { NC } \\
M\end{array}$ & $\begin{array}{l}\mathbf{E} \\
M\end{array}$ & $\begin{array}{l}\mathbf{A} \\
M\end{array}$ \\
\hline Stima de sine & $\begin{array}{c}15.25 \\
\text { low score }\end{array}$ & 6.5 & 11.2 & 15.63 & 11.8 & 16.1 \\
\hline Emoționalitate & 21.92 & 29.5 & 20 & 24.18 & 19.5 & 25.4 \\
\hline
\end{tabular}


Journal of Sport and Kinetic Movement No. 37,Vol. I/2021

\begin{tabular}{|c|c|c|c|c|c|c|}
\hline Sociabilitate & $\mathbf{6 0 . 0 7}$ & $\mathbf{8 5}$ & $\mathbf{7 9}$ & 56 & $\mathbf{6 7 . 6}$ & 59.8 \\
\hline Activism & $\mathbf{7 9 . 2 8}$ & $\mathbf{9 5}$ & $\begin{array}{c}89.2 \\
\text { high score }\end{array}$ & $\mathbf{7 7 . 6}$ & $\mathbf{8 5 . 4}$ & $\mathbf{7 8}$ \\
\hline Curiozitate & $\mathbf{7 3 . 5 7}$ & $\mathbf{8 8 . 5}$ & $\mathbf{7 3 . 6}$ & $\mathbf{7 6 . 3}$ & $\mathbf{7 3 . 7}$ & $\mathbf{7 6 . 8}$ \\
\hline Flexibilitate & 27.28 & $\mathbf{8}$ & 7.4 & 32.8 & 21.6 & 27.4 \\
\hline $\begin{array}{c}\text { Incredere vs. } \\
\text { suspiciune }\end{array}$ & $\mathbf{6 0 . 2 1}$ & $\mathbf{5 0 . 5}$ & $\mathbf{6 0 . 2}$ & $\mathbf{5 8 . 5}$ & $\mathbf{6 3 . 1}$ & $\mathbf{5 5 . 8}$ \\
\hline Politețe & $\mathbf{7 6 . 2 1}$ & $\mathbf{6 4 . 5}$ & $\mathbf{7 6 . 4}$ & $\mathbf{7 4}$ & $\mathbf{7 7}$ & $\mathbf{7 3}$ \\
\hline $\begin{array}{c}\text { Productivitate } \\
\text { average score }\end{array}$ & $\mathbf{8 6 . 4 2}$ & $\mathbf{7 6}$ & $\mathbf{8 3}$ & $\mathbf{8 6 . 1}$ & $\mathbf{8 1}$ & $\mathbf{8 8 . 3}$ \\
\hline Organizare & $\mathbf{8 2 . 3 5}$ & $\mathbf{9 8}$ & 93 & 80.4 & $\mathbf{8 9}$ & $\mathbf{8 0 . 7}$ \\
\hline
\end{tabular}

Note. DC -with direct contact with the opponent; NC - Without direct contact with the opponent; E - Euristic; A Algorithmic;

$M$ - Mean (40-60 average score); With red - the difference is at least 10 points between various.

As mentioned before, due to the small sample of top coaches in team sports, we will be more cautious (and restrained) in interpretation (in the case of this category of specialists). The aspects we will present below refer to the differences between successful coaches taking into account the category of sport practiced (individual sport, with direct contact with the opponent or without direct contact, algorithmic or heuristic) - provided that the difference, in the case of traits personality, to be at least 10 points (see Table 3 ).

Analyzing the table above we catch the following aspects:

- Regarding Sociability (the facet of Extraversion), successful coaches in sports where the contact with the opponent is directly looking for more social interactions (both in professional activity and in free time), compared to specialists in other categories (individual, algorithmic, heuristic sports or those where the contact with the opponent is not direct).

- Regarding Activism (facet of Extraversion) top coaches in sports where the contact with the opponent is direct are more involved in various activities in the social environment, having a faster pace of life, compared to coaches in the following categories : individual sports, algorithmic or in which the contact with the opponent is not direct.

- Referring to Flexibility (the facet of Openness to experience) we note that coaches in sports in which the contact with the opponent is direct tend to support to a lesser extent the traditional modes of action, modeling less their behavior according to the prescriptions of social or religious morality, in comparison with coaches in the other categories. The same can be said about coaches in heuristic sports - compared to specialists who work in sports where contact with the opponent is not direct.

- Investigating the Organization (facet of Conscientiousness) we highlight the fact that coaches with high performance in sports in which contact with the opponent is direct show a stronger orientation to plan and organize their own behavior, are more oriented to approach tasks in a structured way, in comparison with top coaches in individual, algorithmic sports or in which the contact with the opponent is not direct - we must not forget, however, that the level at which this dimension of personality (Organization) is high, in the case of all categories of specialists, the differences being only subtle.

We specify that the low scores in the case of Self-Esteem and Emotionality (facets of Neuroticism) translate into the fact that 
successful coaches have a sense of personal competence, are not discouraged in the face of difficulties and are less vulnerable to stress. Conclusion

Our study contributes to shaping the personality profile of a successful coach. The research presents a typology of top coaches both globally (in the case of the 16 successful coaches investigated) and depending on the category of sport practiced - starting from the combination of scores obtained by specialists for the five major personality factors (BIG FIVE model). The following dimensions were analyzed: impulse control, interaction style, learning style, decision style, anger control, task orientation, defense style, psychological well-being and character orientation.

At the same time, the paper highlights the level at which the facets of the five major personality factors are manifested: Selfesteem, Emotionality, Sociability, Activism, Curiosity, Flexibility, Confidence vs. Suspicion, Politeness, Productivity and Organization. We specify that for half a century (between 1956 and 2004), Romania was, on average, among the top ten countries in the world in terms of performance at the Olympic Games. In 2012, at the Olympic

\section{Authors' Contributions}

All authors have equally contributed to this study.

\section{References}

Gilbert, W., Côté, J., \& Mallett, C. (2006). Developmental paths and activities of successful sport coaches. International Journal of Sports Science \& Coaching, 1(1), 69-76. https://doi.org/10.1260/174795406776338526

Grigore, V., Predoiu, R., Predoiu, A., \& Mitrache, G. (2017). Study regarding relevant abilities of the informal leader in the case of handball players through computerized assessment. Proceedings of the 13th International Scientific Conference "eLearning and Software for Education", 3, 119-126. https://www.ceeol.com/search/articledetail id $=540383$

Iliescu, D., Minulescu, M., Nedelcea, C., \& Ispas, D. (2008). Manual tehnic şi interpretativ NEO $P I-R$ şi NEO-FFI [Technical and interpretive manual NEO PI-R and NEO FFI]. ClujNapoca: Sinapsis.
Games in London, Romania was on the 27th position, and in 2016, at the Olympic Games in Rio de Janeiro, Romania obtained the 47th position. As a result of the COVID-19 pandemic, the Tokyo Olympic Games, from 2020, have been postponed. Future coaches, starting from the results of this research, will be able to intervene in their own professional and personal development, in an attempt to regain the former sport glory - taking into account that the personality is represented by that particular pattern of thoughts, feelings, behaviors, which is not affected by circumstances or time (relative stability is highlighted among the personality characteristics).

Although it is not the only factor, the personality of performance makers (coaches) is certainly one of the very important dimensions that determine the achievement of valuable sports results. In the future, researchers must contribute to shaping the personality profile of a successful coach in the field of sports, knowing that personality is conditioned by the characteristics/ specificity of the sport discipline being trained (Piepiora \& Witkowski, 2020).

Jones, R. L., Armour, K. M., \& Potrac, P. (2004). Sports Coaching Cultures: From Practice to Theory. London: Routledge.

Lounsbury, J. W., Smith, R. M., Levy, J. J., Leong, F. T., \& Gibson, L. W. (2009). Personality characteristics of business majors as defined by the Big Five and Narrow Personality Traits. Journal of Education for Business, 84(4), 200205. https://doi.org/10.3200/JOEB.84.4.200205

Mesquita, I., Borges, M., Rosado, A., \& Batista, P. M. (2012). Self-efficacy, perceived training needs and coaching competences: The case of Portuguese handball. European Journal of Sport Science, 12(2), 168-178. https://doi.org/10.1080/17461391.2010.551413

Mumford, M. D., Todd, E. M., Higgs, C., \& McIntosh, T. (2017). Cognitive skills and 
leadership performance: The nine critical skills. The Leadership Quarterly, 28(1), 24-39. https://doi.org/10.1016/j.leaqua.2016.10.012

Myers, N. D., Park, S. E., Ahn, S., Lee, S., Sullivan, P. J., \& Feltz, D. L. (2017). Proposed sources of coaching efficacy: A meta-analysis. Journal of Sport and Exercise Psychology, 39(4), 261-276. DOI: 10.1123/jsep.2017-0155

Piepiora, P., \& Witkowski, K. (2020). Personality profile of combat sports champions against neo-gladiators. Archives of Budo, 16, 281-293. WOS:000608274500001

Predoiu, R. (Coord.) (2017). Studenţii sportivi se pregătesc pentru jobul potrivit [Sports students are preparing for the right job]. Bucureşti: Discobolul.

Predoiu, A. (2020). Metodologia cercetării ştiinţifice. Aspecte practice şi elemente de statistică neparametrică [Scientific Research Methodology. Practical aspects and elements of nonparametric statistics]. Bucureşti: Discobolul.

Predoiu, R., Makarowski, R., Görner, K., Bota, A., Predoiu, A., Mitrache, G., \& Grigore, V. (2020). Key personality traits of martial arts and world's top coaches - impact on future martial arts specialists. Archives of Budo, 16, 129-142. WOS:000579413000001

Predoiu, A., Predoiu, R., Mitrache, G., Grigore, V., \& Păunescu, M. (2017). Group dynamic in handball teams - the importance of intellectual abilities or how to become the informal leader. Logos Universality Mentality Education Novelty - Social Sciences, VI(2), 32-45.

https://lumenpublishing.com/journals/index.ph p/lumenss/article/view/203

Prophet, T., Singer, J., Martin, I., \& Coulter, T. J. (2017). Getting to know your athletes: Strengthening the coach-athlete dyad using an integrative personality framework. International Sport Coaching Journal, 4(3), 291-304. https://doi.org/10.1123/iscj.20170009

Raportul extins al NEOFFI-Plus. https://romania.testcentral.ro/media/raportextins-neoffi-pdf-3CT3P3VH.pdf

Sheehy, T. L., Dieffenbach, K., \& Reed, P. (2019). An Exploration of Coaching Research in Journal of Applied Sport Psychology from 1989 to 2017. Journal of Applied Sport Psychology, 31(3), 352-365. https://doi.org/10.1080/10413200.2018.149464 2

Zhang, S., Beattie, S., Pitkethly, A., \& Dempsey, C. (2018). Lead me to train better: Transformational leadership moderates the negative relationship between athlete personality and training behaviours. The Sport Psychologist, $\quad 33(2), \quad$ 119-128. https://doi.org/10.1123/tsp.2018-0055 